\title{
Basal icequakes during changing subglacial water pressures beneath Gornergletscher, Switzerland
}

\author{
Fabian WALTER, ${ }^{1}$ Nicholas DEICHMANN, ${ }^{2}$ Martin FUNK ${ }^{1}$ \\ ${ }^{1}$ Versuchsanstalt für Wasserbau, Hydrologie und Glaziologie (VAW), ETH Zürich, CH-8092 Zürich, Switzerland \\ E-mail:walter@vaw.baug.ethz.ch \\ ${ }^{2}$ Institut für Geophysik, ETH Hönggerberg, CH-8092 Zürich, Switzerland
}

\begin{abstract}
Using dense networks of three-component seismometers installed in direct contact with the ice, the seismic activity of Gornergletscher, Switzerland, was investigated during the summers of 2004 and 2006, as subglacial water pressures varied drastically. These pressure variations are due to the diurnal cycle of meltwater input as well as the subglacial drainage of Gornersee, a nearby marginal icedammed lake. Up to several thousand seismic signals per day were recorded. Whereas most icequakes are due to surface crevasse openings, about 200 events have been reliably located close to the glacier bed. These basal events tend to occur in clusters and have signals with impulsive first arrivals. At the same time, basal water pressures and ice-surface velocities were measured to capture the impact of the lake drainage on the subglacial hydrological system and the ice-flow dynamics. Contrary to our expectations, we did not observe an increase of basal icequake activity as the lake emptied, thereby raising the subglacial water pressures close to the flotation level for several days. In fact, the basal icequakes were usually recorded during the morning hours, when the basal water pressure was either low or decreasing. During the high-pressure period caused by the drainage of the lake, no basal icequakes were observed. Furthermore, GPS measurements showed that the glacier surface was lowering during the basal seismic activity. These observations lead us to conclude that such icequakes are connected to the diurnal variation in glacier sliding across the glacier bed.
\end{abstract}

\section{INTRODUCTION}

Icequakes are seismic events inside glaciers, ice streams, frozen lakes or other large bodies of ice. For several decades they have been subject to a variety of studies. One benchmark was set by Neave and Savage (1970), who associated seismic events on Athabasca Glacier, Alaska, USA, with the opening of surface crevasses. Thirty years later Deichmann and others (2000) showed that, although an alpine glacier's seismic activity is dominated by crevasse openings, icequakes can occur at any depth. Whereas seismic emission from glacial ice has been studied in a variety of contexts such as the breaking-off of hanging glaciers (J. Failettaz and others, unpublished information) and glacier calving ( $\mathrm{O}^{\prime} \mathrm{Neel}$ and Pfeffer, 2007; O'Neel and others, 2007), seismic sources near the glacier bed are usually linked to basal motion and subglacial hydrology.

Weaver and Malone (1979) studied seismic events on glacierized volcanoes in the Cascade Range, USA. They reasoned that a number of their detected signals were due to sudden slip motion of the glacier across the bedrock. Métaxian and others (2003) investigated icequakes detected on Cotopaxi volcano, Ecuador. They detected signals which most likely originated from resonances of water-filled ice cavities, which may be activated by ice cracking or sudden changes in water flow near the glacier base.

Basal icequakes have been used to study conditions beneath Antarctic ice streams. Frequent radiation of seismic energy from near the ice-stream base is usually associated with the absence of a deformable sediment layer, which is assumed to be a controlling factor in ice-stream dynamics (e.g. Anandakrishnan and Bentley, 1993; Anandakrishnan and Alley, 1994; Smith, 2006; Danesi and others, 2007).
Stuart and others (2005) studied the seismic emissions from a surging glacier in Spitsbergen, Svalbard. They found that specific basal icequakes may be directly related to the surging process. These icequakes originate from cracks ahead of the surging front, through which water penetrates to the bed. This induces lubrication and heat transfer, which allows the surge front to move down-glacier.

In the present work, we study basal icequakes and their relation to changes in the subglacial water pressure. There are two main processes which induce these pressure changes by altering the water input to the subglacial drainage system: the daily increase in surface melt during the warm hours of the day; and the sudden drainage of Gornersee, a marginal lake at the confluence of the two main tributaries of Gornergletscher, Switzerland. In both cases, we observed increases in water levels inside boreholes of $100 \mathrm{~m}$ or more. Because this study was part of a comprehensive field and modelling investigation of the drainage of Gornersee, we had the opportunity to include data on glacier hydrology and dynamics in the seismic analysis.

The sudden drainage of water masses located inside, beneath or at the margin of a glacier is a well-known phenomenon referred to by the Icelandic term jökulhlaup. During a jökulhlaup, the discharge of affected proglacial streams can increase rapidly, often with hazardous consequences. Peak discharges can differ by several orders of magnitude. Estimates for Pleistocene events are as high as $20 \times 10^{6} \mathrm{~m}^{3} \mathrm{~s}^{-1}$ (Roberts, 2005), whereas the peak discharges of Gornersee are of the order $10 \mathrm{~m}^{3} \mathrm{~s}^{-1}$. The highly destructive potential of jökulhlaups underlines the need for investigations aimed at predicting the magnitude and onset of drainage events (Haeberli, 1983; Richardson and Reynolds, 2000; Björnsson, 2002; Raymond and others, 2003). 


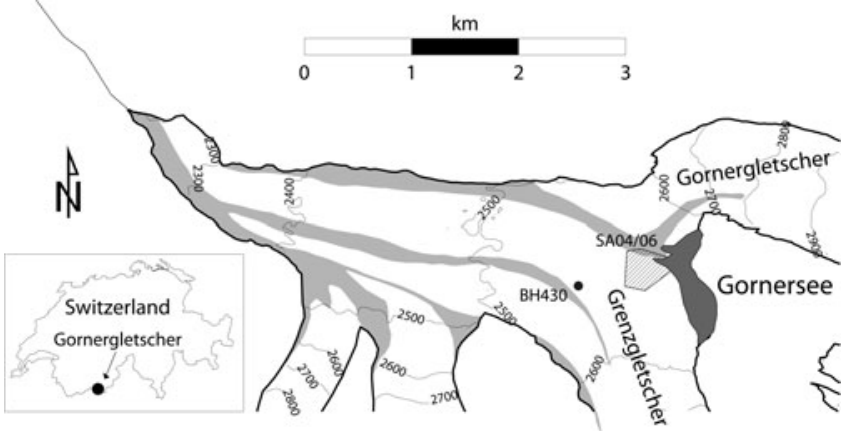

Fig. 1. Overview of Gornergletscher. Gornersee is shown at the confluence area. Contours of surface elevation are in ma.s.l. The grey, shaded areas are debris-covered portions of the glacier. The boundaries of the seismic networks deployed in the field campaigns of 2004 and 2006 are indicated by the hatched area. A pressure transducer was installed at the base of $\mathrm{BH} 430$ in a $430 \mathrm{~m}$ deep borehole drilled to the glacier bed in 2004.

The theoretical treatment of jökulhlaups poses two particular challenges: a description of the initiation mechanism and a description of the flow of water through englacial or subglacial channels. A model describing the evolution of englacial channels as a competition between meltenlargement and creep-closure has been studied and applied to a variety of flood events (Nye, 1976; Spring and Hutter, 1981; Clarke, 2003). These studies, however, do not account for the possibility of brittle deformation of glacier ice. Roberts and others (2000) showed that fracture processes play an important role in the englacial routing of floodwater during a jökulhlaup. They identified hydrofracturing as a mechanism responsible for fracturing the ice. Fractures are driven into the ice above the glacier bed when the hydraulic pressure exceeds the threshold of the overburden pressure plus the tensile strength of the ice. Clarifying the role of brittle deformation of glacier ice during the onset and progress of the drainage event was a major motivation for this study.

\section{FIELD SITE}

The field experiments were conducted on Gornergletscher near Gornersee, which forms annually at the confluence of Gornergletscher and Grenzgletscher located next to the Monte Rosa massif in Switzerland's canton Valais (Fig. 1). The lake can contain up to several million cubic metres of water and drains subglacially almost every summer. For detailed discussions of Gornersee outburst floods, in particular those of 2004 and 2005, the reader is referred to Huss and others (2007) and Sugiyama and others (2007).

At the initiation of the outburst floods, the lake volumes in 2004 and 2006 were of comparable sizes at about $4 \times 10^{6} \mathrm{~m}^{3}$. In 2004, the lake drained subglacially with peak discharges of about $15 \mathrm{~m}^{3} \mathrm{~s}^{-1}$. A rapidly rising discharge curve and large uplifts of up to $3 \mathrm{~m}$ of the glacier surface (Weiss, 2005) near the lake suggest ice-dam flotation as a possible triggering mechanism. In 2006, Gornersee drained across the glacier surface. The lake level rose until a narrow lake arm reached a nearby moulin. The overflowing lake water almost immediately filled the moulin, raising its water level to that of the lake. After about 1 day, the moulin had adjusted to the large amount of lake water input. Consequently, a strong current developed inside the lake arm. The water
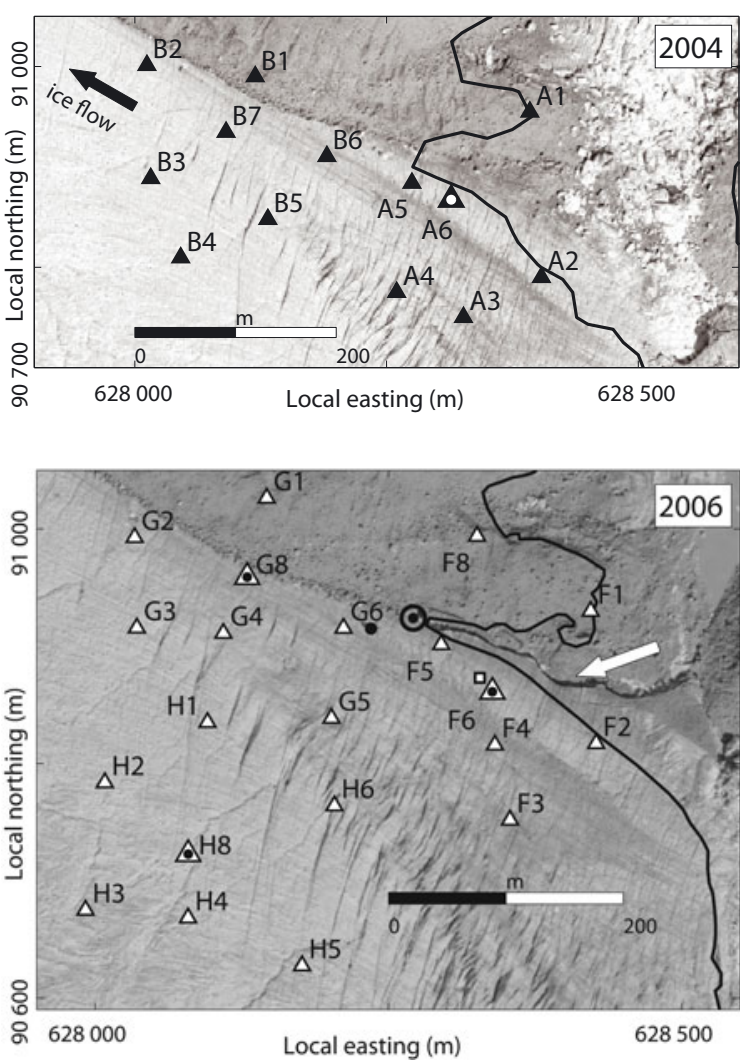

Fig. 2. Ortho-photographs of the seismic network areas in 2004 and 2006. The seismometers are indicated by triangles, and a global positioning system (GPS) unit by a white square (2006). At the locations of the large triangles with dots, a surface as well as a deep borehole seismometer was installed. A black dot indicates the position of a $150 \mathrm{~m}$ deep borehole $(\mathrm{BH} 6)$ to the glacier bed equipped with a pressure transducer (2006). The solid curve represents the maximum lake level. The circled dot (lower) indicates the position of the moulin into which the lake drained in 2006, incising a canyon into the ice (white arrow). Coordinates of the Swiss Grid are shown.

flow gradually melted a spillway into the ice, converting the lake arm into a fast-flowing stream. The slow deepening of the canal formed a canyon and only allowed for peak discharges of less than $5 \mathrm{~m}^{3} \mathrm{~s}^{-1}$.

\section{SEISMIC SET-UP AND INSTRUMENTATION}

Figure 1 shows the locations of the seismic networks installed in 2004 and 2006, consisting of 14 and 24 seismometers, respectively. Other measurement sites relevant to this work are shown in the detailed maps of the seismic arrays in Figure 2.

The set-up consisted of three-component seismometers recording the velocity of ground motion in direct contact with the ice. The analogue seismic signals were converted to digital signals by a seismic recorder (Geode by Geometrics). Up to eight seismometers could be linked to one geode. The geodes applied an anti-aliasing low-pass filter, whose frequency response decreased by $3 \mathrm{~dB}$ at $83 \%$ of the Nyquist frequency. Apart from an analogue-to-digital high-pass filter, which only affected frequencies below $2 \mathrm{~Hz}$, no additional filters were applied at the recording stage. The geodes were linked in series via an ethernet cable. A laptop computer equipped with an external hard disk was connected to the Master Geode and served as a storage device. 
Synchronization of all channels is guaranteed by the recorder, while absolute time is provided by the laptop-computer clock.

The majority of instruments were $1 \mathrm{~Hz}$ seismometers (Lennartz LE-3D, referred to as surface seismometers) placed on the glacier surface. The manufacturer specifies a flat frequency response up to $80 \mathrm{~Hz}$. Surface melt required daily leveling of these instruments. In addition, $28 \mathrm{~Hz}$ geophones (Geospace GS-20DH, referred to as deep-borehole seismometers) were placed in boreholes drilled with a hot-water drill to depths of 50-250 m.

In 2006, six additional $8 \mathrm{~Hz}$ borehole seismometers (Geospace GS-11D, referred to as shallow borehole seismometers) were installed at a few metres below the surface. The frequency response was assumed flat for both types of borehole seismometers, at least up to the corner frequency of the anti-aliasing filter.

An amplification of $24 \mathrm{~dB}$ and $36 \mathrm{~dB}$ was applied to the surface seismometers and the borehole seismometers (both $8 \mathrm{~Hz}$ and $28 \mathrm{~Hz}$ devices), respectively. Table 1 summarizes the values of recording parameters that differed in the two field seasons. Because the recorders were not equipped with the software module necessary for continuous recording, only events detected by an automatic self-trigger algorithm were recorded.

The trigger operates in the following way. A root-meansquare (rms) value of two concurrent time windows is computed. The rms values over the previous $800 \mathrm{~ms}$ long-term average (LTA) window and the previous $80 \mathrm{~ms}$ short-term average (STA) window are calculated and compared. When the ratio $\gamma=$ STA/LTA exceeds a given threshold (Table 1 ), that station is said to have triggered. In order to initiate recording, a minimum of $n_{\text {trig }}$ channels had to satisfy the trigger condition. The trigger algorithm was applied to all three channels of each seismometer. Since for both years $n_{\text {trig }}>3$, a single three-component seismometer could not trigger the system. Once activated, recording took place for $t_{\mathrm{rec}}(\mathrm{s})$. The recording window also included the signal detected prior to triggering, indicated by $t_{\text {pre. }}$ In order to avoid multiple triggering per event, the trigger remained unarmed for a few tenths of a second after event detection.

\subsection{4 configuration}

In 2004, 14 surface and 1 deep borehole seismometer (100 m depth) were operational between 15 June and 8 July (Fig. 2). The seismometer names were selected according to the geode they were connected to. Two geodes were used for the 2004 network, each connected to seven seismometers. Geode A served as the Master Geode, to which the recording laptop computer was connected.

\subsection{6 configuration}

In 2006, the seismic set-up consisted of 15 surface seismometers, 3 deep-borehole seismometers (at depths of 40, 140 and $250 \mathrm{~m}$ ) and 6 shallow-borehole seismometers, operational between 29 May and 28 July (Fig. 2). Three geodes $(\mathrm{F}, \mathrm{G}$ and $\mathrm{H})$ were used to connect the seismometers to the recording laptop computer located at Geode F (Master Geode). Figure 2 also shows the location of the moulin, into which the lake drained. Less than $40 \mathrm{~m}$ away, a borehole (BH6) had been drilled to the glacier bed and a pressure transducer installed. This allowed us to monitor the basal water pressure in the vicinity of the moulin. As the lake drained into the moulin, these measurements were particularly valuable.
Table 1. Recording specifications (the value of $t_{\text {pre }}$ was changed several times in 2006 to values within the given range)

\begin{tabular}{lcc}
\hline & 2004 & 2006 \\
\hline Sampling frequency $(\mathrm{Hz})$ & 1000 & 4000 \\
Threshold ratio & 10 & 20 \\
$n_{\text {trig }}$ & 4 & 10 \\
$t_{\text {rec }}(\mathrm{s})$ & 2 & 1 \\
$t_{\text {pre }}(\mathrm{s})$ & 0.5 & $0.4-0.5$ \\
\hline
\end{tabular}

\section{SEISMIC DATA}

During the 2004 and 2006 field seasons, approximately 35000 and 50000 seismic events were detected, respectively. As expected (Neave and Savage, 1970; Aschwanden, 1992; Deichmann and others, 2000), the vast majority of the recorded signals were due to seismic sources close to the surface, probably associated with the opening of crevasses. Less than $0.5 \%$ of all recorded events have been located at depths below the crevassing zone. However, these events are of particular interest in the context of this study, as they may be related to water propagation through sub- or intraglacial channels.

\subsection{Identification of deep events}

Because of the large number of recorded seismic signals, a form of automated signal recognition had to be used. We developed two techniques to identify the seismograms of deep icequakes among the large datasets: an automated waveform discriminator, based on the presence or absence of the Rayleigh phase, and a cross-correlation search.

The seismograms of deep icequakes show substantial differences to those originating from shallow depths (Deichmann and others, 2000). The P-wave recorded by nearsurface sensors is very impulsive and strongest on the $z$-component. Additionally, the Rayleigh phase which is characteristic of signals of shallow icequakes is missing or much less pronounced in the records of deep events. Since the Rayleigh phase produced by shallow icequakes is of lower frequency than P- and S-phases, which dominate the deep icequake signals, the frequency of the dominant phase can be used as an automated waveform discriminator.

Once the waveform discriminator finds a set of deep events based on the frequency content, a time-domain crosscorrelation can be used to find events with similar seismograms. We cross-correlate the $z$-component time series of a 'master' event with those of all other events detected in that particular field season. Each track is cross-correlated independently, which means that each track may show a maximum cross-correlation at a different lag. The spread in lag differences $s_{\text {lag }}$ and the maximum cross-correlation coefficient $R_{\max }$ are used to quantify waveform similarity. Perfect similarity is indicated by $R_{\max }=1$ and $s_{\text {lag }}=0$. The crosscorrelation search identified up to several dozens of events with similar seismograms that had previously been missed by the waveform discriminator.

\subsection{Hypocentre location procedure}

The icequake locations were found using a procedure described by Lee and Steward (1981). An inversion algorithm searches for locations in space yielding theoretical P- and $\mathrm{S}$-arrival times as close to the hand-picked ones as possible. 


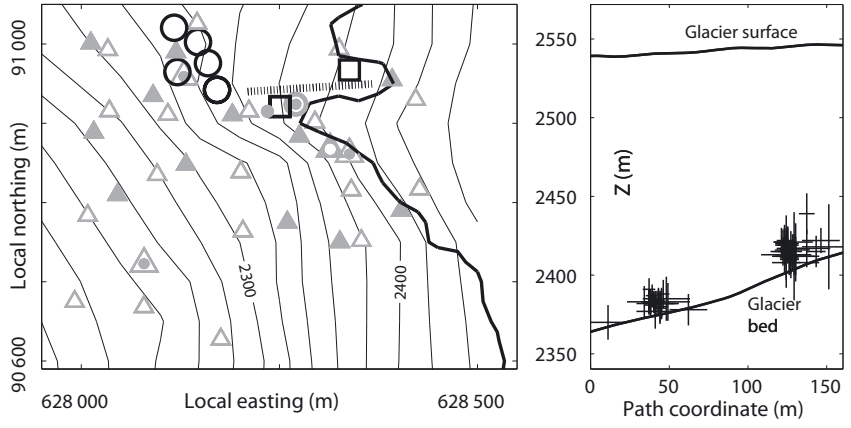

Fig. 3. Left: epicentres of deep icequake clusters detected in 2004 (big empty squares) and 2006 (big empty circles). Empty and solid triangles represent the 2004 and 2006 seismic stations, respectively. The contours approximate the glacier bed elevation (ma.s.l.) (Huss, 2005). The dashed line indicates the vertical cross-section path to show the hypocentral locations of the icequake clusters. Right: hypocentres of the two 2004 clusters. The crosses indicate the icequake locations and uncertainties.

The theoretical arrival times were calculated with seismic velocities input by the user. Specifying higher velocities for the deep-borehole seismometers accounted for crevasses and fissures near the glacier surface known to cause a slower seismic velocity zone within the upper $20 \mathrm{~m}$ (Gischig, 2007).

The seismic velocities which we used were determined via a set of explosions at distinct locations throughout the seismic network. The arrival-time accuracy was usually $5 \mathrm{~ms}$ or better. The uncertainties in locations are given by one standard deviation of the location errors calculated from the diagonal elements of the inverse normal equations scaled by the assumed timing errors. The uncertainties were usually no larger than $10 \mathrm{~m}$ in all directions. In some instances, however, they were as high as $30 \mathrm{~m}$. The vertical component was generally subject to larger uncertainties than the horizontal component.

\section{RESULTS}

\subsection{Deep icequake locations}

\section{4 locations}

More than 80 deep events were identified and located in the summer of 2004. Most of these are clustered in two distinct regions near the glacier bed. The epicentres of the remaining deep events are outside the seismic array. Consequently, the quality of their locations is poor and does not allow for further analysis of their source depths and possible clustering activity. Figure 3 shows the epicentres of the two basal clusters inside the seismic network. The clusters contain about 30 events each, and their signals show a high degree of similarity, making them very suitable for the crosscorrelation search and suggesting that they have similar source mechanisms.

The hypocentres are located at depths of $150 \mathrm{~m}$. This corresponds closely to the glacier thickness as determined by radio-echo soundings (Huss, 2005). These thickness measurements, however, can contain an error of up to $20 \%$ of the thickness. Taking the uncertainties of the icequake locations also into consideration, we cannot determine at this point whether the icequakes are at the ice-bedrock interface, just above or just below it. The signals of the westernmost 2004 cluster (Fig. 3) show a higher degree of similarity than

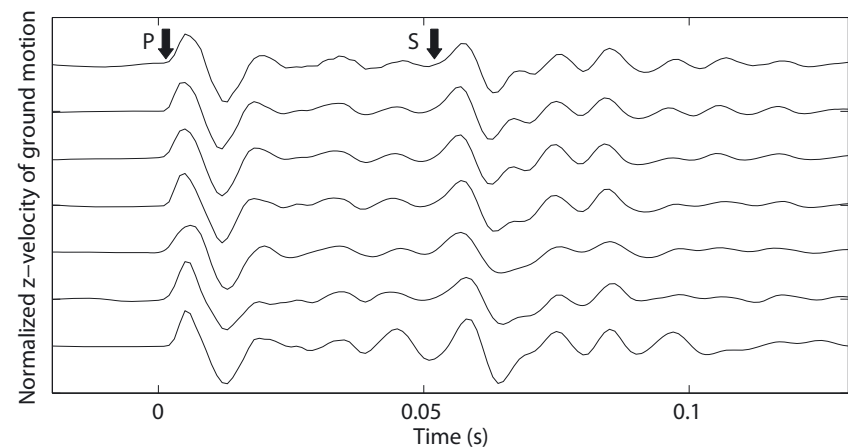

Fig. 4. Vertical velocity seismograms of a subset of icequakes belonging to the western 2004 cluster, all recorded at station A6 (Figs 2 and 3). P- and S-arrivals are indicated. A second-order causal Butterworth bandpass filter with corner frequencies of 5 and $80 \mathrm{~Hz}$ was applied to each signal. The events were recorded between 15 and 20 June 2004. Among the events belonging to this cluster, they show the highest degree of similarity (i.e. $R \geq 0.86$ for the entire waveform and $R \geq 0.98$ for the first $\mathrm{P}$-arrival).

those events belonging to any other cluster detected in 2004 and 2006.

Figure 4 shows the first seven recordings from this cluster, which occurred over a period of about 1 week. The events belonging to this subset show particularly high coherence. Any pair of seismograms belonging to this subset yields a correlation coefficient $R \geq 0.86$ when using the entire waveform, and $R \geq 0.98$ when using the first P-arrival only (using a bandpass filter between 5 and $80 \mathrm{~Hz}$ ).

As in most of the basal icequakes considered in this study, signals of those shown in Figure 4 lasted between 0.1 and $0.2 \mathrm{~s}$ at all stations. Figure 4 also shows typical impulsive P-arrivals, which are particularly pronounced on the vertical component. The second main phase is the direct S-arrival, whereas no significant Rayleigh wave can be seen.

As well as the two basal clusters, about 25 deep icequakes located about $500 \mathrm{~m}$ northwest of the array were found. For these, the location quality in all dimensions is very poor (uncertainties of up to $100 \mathrm{~m}$ ). This is due to the bad azimuthal coverage of recording seismometers. However, the signals show impulsive first arrivals, which is typical for deep icequakes. Furthermore, the first motions of the P-waves recorded at the deep- borehole seismometer indicate that the hypocentres lie at depths comparable to the depth of this seismometer $(100 \mathrm{~m})$. Whereas the clustered events lying within the network have pronounced P- and S-phases, the signals of the deep events lying outside the seismic network have little or no S-energy.

\section{6 locations}

The set of deep icequakes detected in 2006 shows several differences to that of 2004. The total number in 2006 was nearly 200, as opposed to about 80 in 2004. This may be partially due to the larger seismic array. Similar to 2004, the majority of the 2006 basal icequakes show clustering. However, about 40 deep icequakes in the 2006 set were not associated with a cluster. Of these 40 scattered events, more than half were reliably located at intermediate depths within the ice. Their sources were therefore unlikely to be associated with surface crevassing, which is confined to depths of about $20 \mathrm{~m}$ (Paterson, 1994), or with basal brittle fracture. Deichmann and others (2000) found only one such event on 
Unteraargletscher, Switzerland. Although the location quality was good, it seemed questionable that among over 300 located icequakes on Unteraargletscher, only one occurred at intermediate depths and several dozens occurred near the glacier base.

Figure 3 shows the region of highest activity, containing five clusters with over 120 events. The size of the clusters varies significantly: they contain between $\sim 10$ and 50 icequakes. Most deep icequakes show the typical impulsive P-arrivals which are usually compressive, possibly indicating an isotropic source. However, unlike in 2004, some events also show dilatational first arrivals which may be evidence for a deviatoric source.

\subsection{Icequake activity}

Variations in icequake activity on different timescales are now discussed. The focus is directed to the 2004 and 2006 basal-cluster events depicted in Figure 3. As will be shown, the activity of the basal-cluster events reaches its maximum during times when the remaining seismicity, consisting almost exclusively of surface icequakes, is relatively low.

\section{Influence of trigger}

Water flow on the surface and within the glacier can substantially increase the seismic background noise of the glacier and thus decrease the trigger sensitivity of the instruments. Enhanced water flow can be the result of precipitation events. Precipitation records of 2004 and 2006 show several such events throughout the summer. We scrutinized the datasets to determine if the timing of precipitation events may have introduced a substantial bias to the trigger sensitivity and thus event detection. The patterns in event detection presented here show no systematic dependence on the occurrence of precipitation events. Regarding changes of seismic activity on a diurnal scale and with respect to the lake drainage, we therefore conclude that the changing trigger sensitivities induced by precipitation events may be neglected.

The diurnal surface melt cycle does, however, induce a considerable trigger bias. During the day, meltwater runoff into streams and moulins increases the seismic background noise of the glacier. Because the trigger is effectively measuring the signal-to-noise ratio (using the STA/LTA threshold), as noise increases the trigger sensitivity decreases. This means that the trigger is more sensitive at night or in the early morning hours. As we are concerned with secular variations in seismic activity, we must account for variations in trigger sensitivity that could falsely be interpreted as seismic activity variability. In this section and in section 5.3, the approach to this problem is explained in detail using the 2004 set of recorded signals. An equivalent procedure was applied to the 2006 data.

The changing trigger sensitivity also affects the performance of the waveform discriminator. Events with high signalto-noise ratios are more easily identified, a characteristic that deep events during the night are more likely to possess than those during the day. The cross-correlation technique, however, is less sensitive to changes in background noise, as prior to performing the cross-correlation the signals are bandpassfiltered between 5 and $200 \mathrm{~Hz}$.

Because the majority of identified deep icequakes occur in clusters and have similar signals (Figs 3 and 4), the crosscorrelation technique detects these events efficiently once a single or a few members of the cluster are found. If events were only found via the waveform discriminator it would be difficult to judge whether their occurrence reflects actual seismic activity or merely a time of low background noise with high signal-to-noise ratios. On the other hand, the cross-correlation technique permits event detection that is less sensitive to background noise. Therefore, we have only analyzed clusters whose event detection was via the crosscorrelation technique.

In order to investigate the changing trigger sensitivity, the relative strengths of the recorded signals were determined. For each event, the median of the maximum amplitudes of all seismometers was computed. Figure 5 a shows the result for the 2004 data. Varying on a diurnal scale, as expected, the median count level of the weakest signals can be used as a proxy for trigger sensitivity. At night, signals can be recorded that would be too weak to trigger the system during the day. Therefore, these 'weak' events may reflect the trigger sensitivity rather than diurnal variations in seismic activity. From Figure 5a we assume that above a median count level (calculated by taking the median of the maximal amplitudes at all 14 seismometers) of 1000 counts (horizontal line in Fig. 5a), the recorded events form a complete set ('strong' events), meaning that they would be strong enough to trigger recording at any time of day.

For the 2006 data, those events subject to changing trigger sensitivities were determined in the same manner. The only difference is that the threshold was found to be 2000 counts, twice as high as in 2004. The reason was that the low-level cut-off of icequake median counts is not as clear as in 2004. This is most likely an effect of the different trigger settings (Table 1) and the larger number of seismometers.

To confirm the robustness of the cross-correlation search with respect to seismic background noise, we conducted search runs with 2004 basal-cluster signals to which we artificially added noise. The goal was to examine if signals with added daytime noise generally do not pass the search criteria whereas those with night-time noise do. In that case, the changing background noise of the glacier strongly influences the performance of the cross-correlation search.

The noise time series was extracted from a $0.5 \mathrm{~s}$ pre-event time window of the regular $2 \mathrm{~s}$ event files. The $0.5 \mathrm{~s}$ of seismic noise was then concatenated with itself to a $2 \mathrm{~s}$ noise time series. For each day during which basal-cluster icequakes were detected, 24 noise seismograms were constructed, each containing noise from a different hour of the day. To these noise time series we added the basal-cluster signals of the same day. We then performed the cross-correlation search on each cluster using the time series that consisted of the sum of noise and signal.

From the 24 strong basal-cluster events that were found in 2004, 17 events were detected by the cross-correlation search in all cases of added noise. Three events were no longer detected during several or all hours during both day and night. Two events failed detection with daytime noise while passing detection with night-time noise. However, this was only the case during one or two afternoon hours. Only two events were so weak that they could only be detected during low-noise morning hours. We therefore conclude that for the majority of strong basal-cluster events, detection via cross-correlation search is not sensitive to changing seismic background noise.

\subsection{Background glacier seismicity (2004)}

Before the lake drained, 20-100 events per hour were recorded (Fig. 5b). Note that between 25 and 29 June only one 


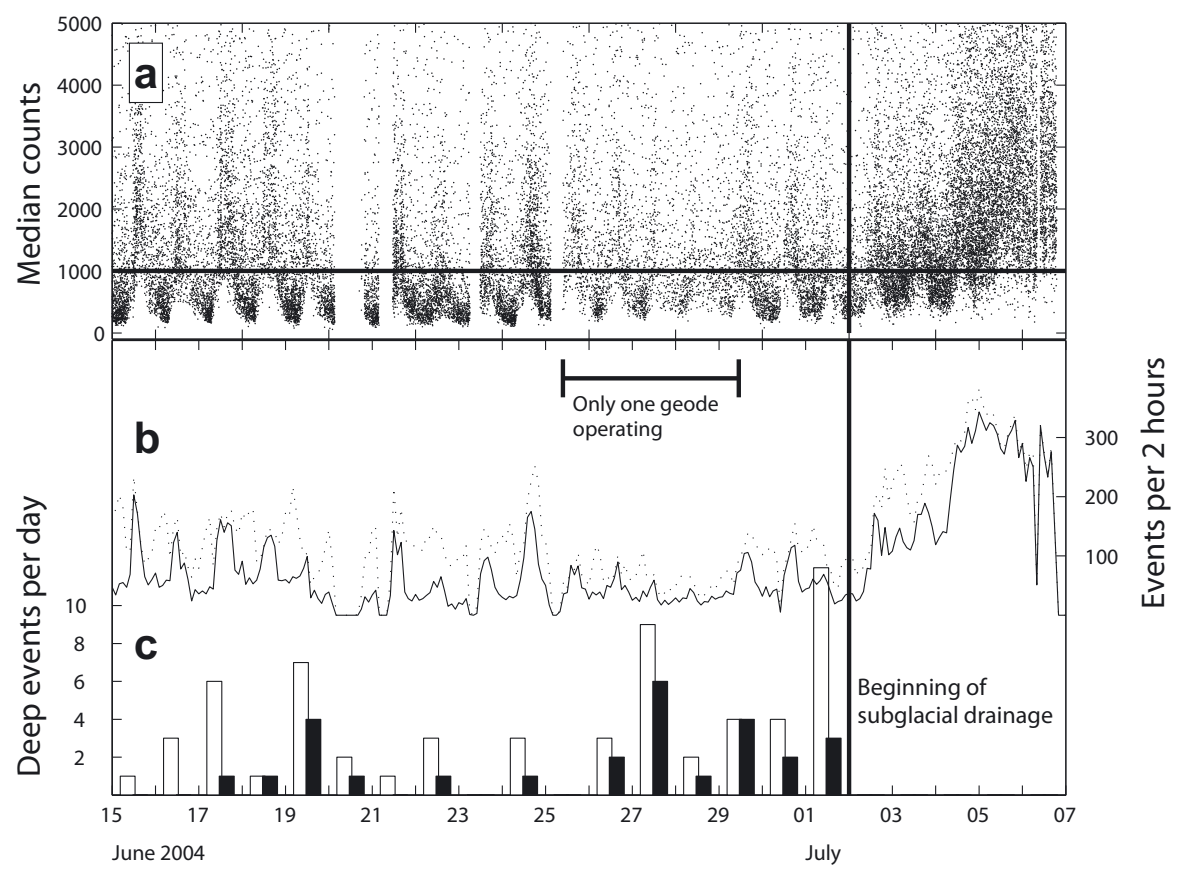

Fig. 5. Seismic activity on Gornergletscher measured by the 2004 seismic array. (a) Each black dot corresponds to one recorded event. For illustration purposes, the strongest $10 \%$ of the signals are not shown. Missing data on 20,21, 23, 25, 29, 30 June and 6 July are due to instrument malfunctions. Between 25 and 29 June, only the seven seismometers of Geode A were operating. (b) Seismic activity in bins of 2 hours. The dotted curve includes all recorded signals, and the solid curve only those with median counts above 1000. (c) Histogram of the activity of deep events. Empty columns include all events belonging to the 2004 clusters shown in Figure 3, the solid columns only those with median counts above 1000. Note that no basal-cluster events were detected after the beginning of the lake drainage.

geode was operating, which is the probable cause of reduced daily peaks. As the lake drained, the number of strong events increased to more than 150 per hour on 5 July. During the first half of the drainage, the fraction of weak icequakes was significantly larger than during the maximum of the seismic activity on 5 July, when the large majority of recorded icequakes passed the median count cut (Fig. 5b). It is difficult to assess the meaning of this observation, since the locations of these icequakes have not been determined. The change in relative abundance of recorded weak and strong signals may be due to changes in location, source strength or different levels of seismic background noise.

As shown in Figure 5c, up to 12 basal-cluster events per day were found. Almost half of them are strong enough to pass the median count cut. On 1 July, just prior to the lake drainage, 12 basal-cluster events occurred. Although most of them are weak, this seems to mark a period of high activity. During the following days, while Gornersee drained (between 2 and 7 July which marks the end of the recording), no more basal-cluster events were detected. Yet on 2, 3 and 4 July the night-time seismic noise level appears to be low enough to allow recording of weak basal-cluster events as on 1 July. After 5 July, the lake drainage seems to increase the seismic background noise significantly (Fig. 5a). This probably inhibits recording of weak events even during the night.

\subsection{Diurnal activity}

It is clear from Figure $5 b$ that the activity of icequakes shows significant variations within a diurnal range. To illustrate these variations, the icequake occurrence (source times) stacked for each hour of the day is shown in Figure 6. Only days that show no gaps in recording were used for this stack (Fig. 5 caption). The icequake activity as determined from all strong recorded signals (black solid curve) reaches a daily maximum in the early afternoon. During night-time and morning hours the activity is much lower. This is expected since during the warm hours of the day, glacier flow reaches a maximum due to basal sliding. Note that the diurnal signal in activity does not appear when including the weak events (dotted curve). We suggest that the larger number of recorded weak events compensates for the actual lower activity rate at night.

The small subset of basal-cluster events shows a different diurnal variation (Fig. 6a); none of the strong basal-cluster events occur during the times of maximum seismic activity shown by the black curve. Instead, they tend to occur during the early morning hours or late at night when the overall seismic activity reaches a low.

As can be seen in Figure 6b, the data of 2006 reproduce these diurnal fluctuations in icequake activity. Again, when considering the set of 'strong' icequakes, the overall seismic activity reaches a maximum between early and late afternoon. On the other hand, the activity of basal-cluster events is highest during night-time and the early morning hours.

The systematic occurrence of the stronger deep icequakes, which is opposite to that of the overall seismic activity, is a central point of the present work. This is a robust observation because potential biases of the diurnal variations of the trigger sensitivity were accounted for by considering only those icequakes above the median count threshold. Furthermore, as we showed above, the daytime seismic background noise is not strong enough to prevent detection of strong basalcluster icequakes via cross-correlation search.

In order to stress this point, consider the 17 strong basalcluster events that are detected despite the addition of daytime noise. None of the basal-cluster events of 2004 occurred between 1200 and $2000 \mathrm{~h}$, an 8 hour long time window. If 

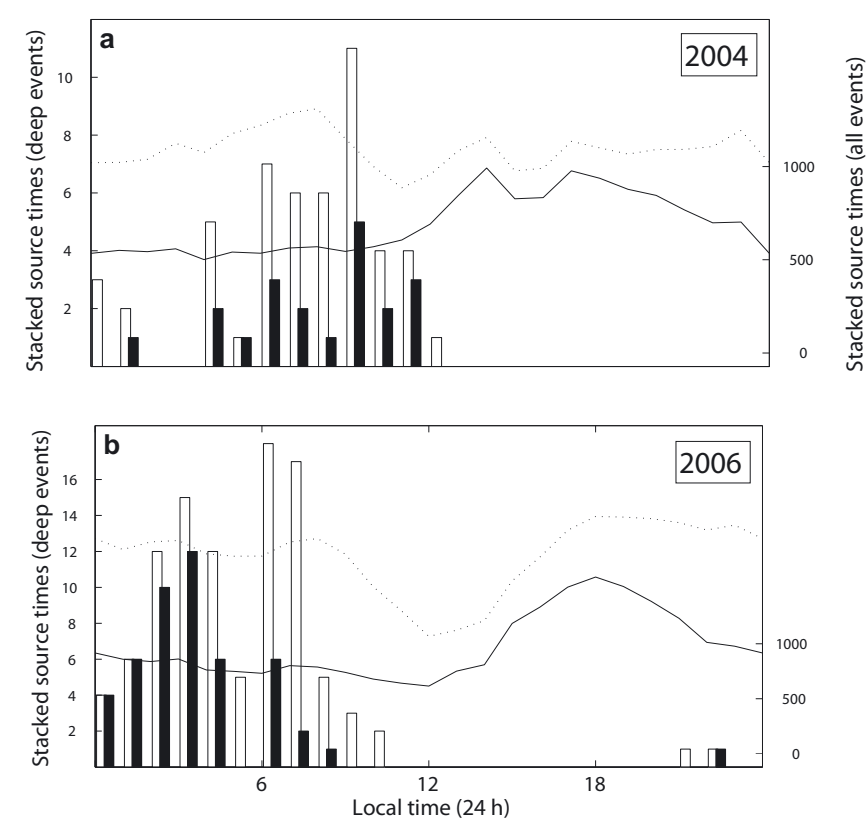

Fig. 6. Stacked times of icequake occurrences ('source times') for 2004 (a) and 2006 (b). The histogram shows the stacked source times of deep icequakes. Empty columns correspond to all basalcluster events, and solid columns to those above the median count cut. The dotted curve shows the stack for all detected events (shallow or deep). The solid curve represents the subset of events passing the median count cut.

the 17 strong ones occurred randomly throughout the day and independently of each other, then the probability of not detecting any of them between 1200 and $2000 \mathrm{~h}$ would be $(1-8 / 24)^{17}=0.001$. We therefore attribute the systematic detection of basal-cluster icequakes during night-time hours to changing source activity and not to changes of the detection threshold due to diurnal variations of the seismic background noise.

\section{DISCUSSION}

The analysis of the diurnal activity of the basal-cluster icequakes demonstrated the following main results. First, strong basal-cluster events occur predominantly in the morning hours or late at night. Second, the overall seismic activity of the glacier, in contrast to that of the basal-cluster events, is maximal in the afternoon. Third, there is no evidence that the lake water input leads to an increase in basal-cluster events. In fact, during the 2004 subglacial drainage and at the onset of the 2006 overflow of Gornersee, no basal-cluster icequakes were detected.

These results cannot be explained by hydrofracturing, by which cracks are opened up with high water pressures. If this were the process responsible for the basal-cluster events, high source activity would be expected during the warm hours of the day when meltwater enters the subglacial drainage system with the potential to drastically increase basal water pressures. In addition, the influx of water due to the lake drainage alters the subglacial hydrological conditions to favour rather than suppress hydrofracturing.

\subsection{Comparison with basal water pressure}

A comparison between the source times of basal-cluster icequakes and the time series of basal water pressures measured
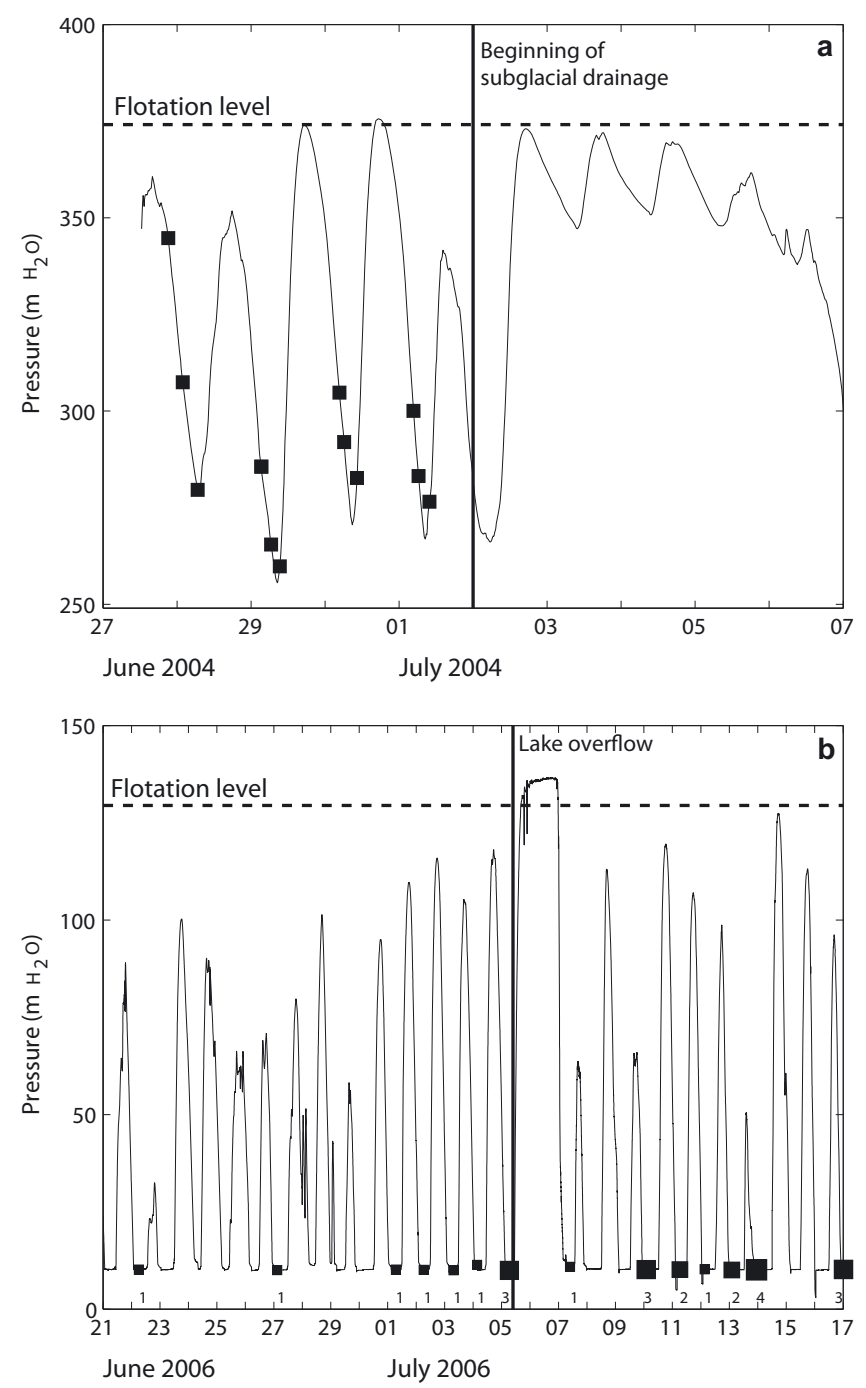

Fig. 7. Basal water pressures as measured in boreholes $\mathrm{BH} 430$ (a) and $\mathrm{BH} 6$ (b). The pressure sensor in borehole $\mathrm{BH} 6$ was installed about $20 \mathrm{~m}$ above the bed, resulting in a low-pressure cut-off whenever the water level sank below the pressure sensor. The solid vertical line marks the beginning of the lake drainage events for each year. Superimposed on the pressure time series are the source times of the 'strong' basal-cluster icequakes of that year (black squares). For 2006, the size of the squares indicates how many icequakes occurred during that time period (number below). Note that the basal-cluster icequakes occur only at pressure decreases or near minima.

in nearby boreholes is further evidence against hydrofracturing. Figure 7 shows the pressure-sensor data from boreholes BH430 (2004) and BH6 (2006). Their locations are given in Figures 1 and 2. Whereas borehole BH430 was somewhat remote from the 2004 seismic network and the basal-cluster events detected that year (about $800 \mathrm{~m}$ from the centre of the seismic array), borehole $\mathrm{BH} 6$ was drilled in the immediate vicinity of the 2006 cluster and of the moulin that the lake drained into (Fig. 3).

Prior to the lake draining, both time series show large diurnal pressure fluctuations of up to $100 \mathrm{~m}$ or more which almost reach flotation level during pressure peaks. This is evidence for the good connection of the boreholes to the subglacial drainage system. During the 2004 lake drainage, for about 4 days, the basal water pressure remained high even during night-time when it usually drops. Diurnal pressure 


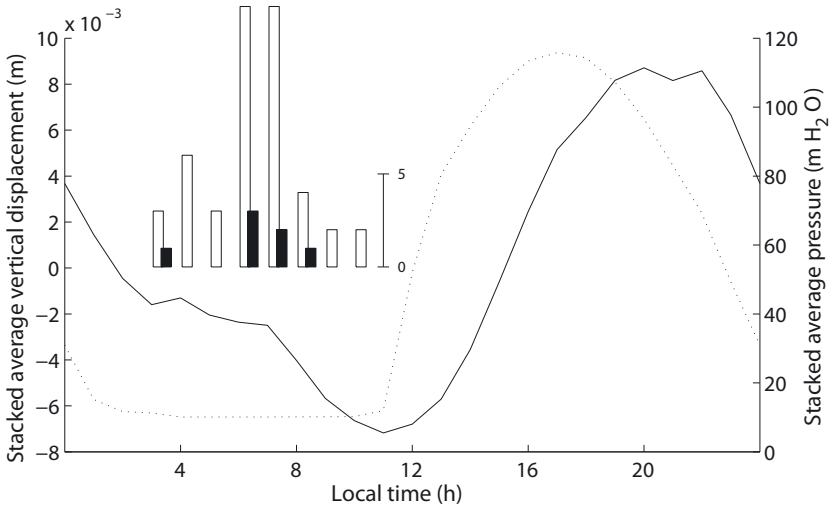

Fig. 8. Comparison between surface uplift (solid curve), basal water pressure (dotted curve) and the source times of basal- cluster events (histograms) between 1 and 5 July 2006. Empty columns represent the stacked source times of all detected basal-cluster events and solid columns represent strong events. The surface motion and basal water pressure were measured with a GPS unit near station F6 and inside borehole BH6, respectively (Fig. 2). Note that the basal-cluster icequakes occurred at times when the surface was lowering.

fluctuations are therefore much less pronounced. Note that the pressure rise is not exactly coincident with the beginning of the lake drainage. This time lag may be due to the distance between lake and borehole. It is also difficult to define an accurate beginning of the 2004 drainage event, since superglacial drainage and ice-dam flotation preceded or accompanied the subglacial drainage (Huss and others, 2007).

In 2006, a similar pressure rise was observed during the beginning of the drainage. Again, for about 2 days, the water pressure did not fall during the night. This high pressure level was also observed at the surface. Once the lake overflowed into the moulin, it quickly filled it so that the water level reached the glacier surface. However, unlike in 2004, the subglacial drainage system adjusted to the water input after about 1 day and the diurnal pressure fluctuations manifested themselves once again.

Figure $7 \mathrm{a}$ and $\mathrm{b}$ also indicate the source times of the basalcluster events in 2004 and 2006. In 2004, all cluster events occur on the falling limbs of the diurnal pressure peaks. None occur at the pressure peaks. Furthermore, no basal-cluster icequakes occur just prior to and during lake drainage.

The 2006 basal-cluster events (Fig. 7b) occur almost exclusively at the lowest pressures measured on the day of their occurrence. As in 2004, no basal-cluster events were detected during the high-pressure period of the lake drainage. Basal-cluster events were recorded again after the moulin saturation when pressure fluctuations resumed.

Summarizing the comparison between the diurnal fluctuations of basal-cluster icequake activity and basal water pressure, it can be stated that there is no evidence that high water pressures cause basal icequakes. Instead, these seismic events seem to occur during low or decreasing water pressures. It is therefore unlikely that hydrofracturing is the cause of these seismic events.

\subsection{Comparison with surface motion}

Between 1 and 5 July 2006, continuous global positioning system (GPS) measurements are available from a receiver installed near station F6 (Fig. 2). Figure 8 shows the (average) stacked surface uplift for this time period. The accuracy of a single GPS measurement is $\pm 0.3 \mathrm{~cm}$ (Sugiyama and Gudmundsson, 2004). The figure also shows the stacked basal water pressure during the same period as measured in borehole $\mathrm{BH} 6$, as well as the temporal occurrence of basal-cluster events detected in this time period.

The GPS data were very noisy and were smoothed before stacking. This was done using a moving-average filter given by the function $\left[1-(d / w)^{2}\right]^{2}$, where $d$ is the distance in time from a data point to the centre of the filter and $w=4$ hours is the filter length. In addition, an overall trend was subtracted from the time series. It should be mentioned that the GPS data were too noisy for time derivatives of the horizontal coordinates to reliably determine diurnal fluctuations in horizontal surface velocities.

The surface uplift shows a pronounced diurnal fluctuation. The peak is reached at around $2000 \mathrm{~h}$ local time, whereas the minimum occurs just before noon. The surface lowering during the morning hours is interrupted by a small bump starting at around $0400 \mathrm{~h}$. This feature can also be seen in the unstacked data. The origin of this change in lowering rate is unknown.

These fluctuations from the overall trend have an amplitude of about $1 \mathrm{~cm}$, which is several times smaller than the diurnal uplifts observed further down on the glacier tongue (Weiss, 2005; Huss and others, 2007). The reason for this is probably that, further down, the glacier bed becomes horizontal. This allows for the temporary storage of daily meltwater with the potential to lift up the glacier over larger regions. However, under the seismic study site, only the glacier's surface is horizontal, whereas its bed is strongly inclined (Fig. 3). Meltwater runs down this incline and can only be stored in small quantities in local depressions. A large uplift of the glacier over larger areas is therefore not possible.

Figure 8 shows the key relationship between surface uplift and the source times of the basal-cluster events. The latter occur exclusively during the period of surface lowering. Considering also the weak events (empty bars), the figure suggests that the basal-cluster events may be related to the bump that interrupts the overall lowering of the surface. Another interesting observation is that the surface uplift reaches its maximum after that of the basal water pressure. Sugiyama and Gudmundsson (2004) made the same observation on Unteraargletscher.

\subsection{Source mechanism}

A central yet unanswered question that arises from this investigation is: what mechanism causes basal clustering of icequakes? The seismic moment tensors of these events would give quantitative information about fault geometry and strength and failure mechanism (e.g. double-couple or isotropic) and are therefore of high value in answering this question. As a second step, modelling glacier flow subject to strong changes of basal boundary conditions can provide clues about the deformation of basal ice layers. The modelled stress and strain fields can help explain why the fracture types as given by the moment-tensor solutions occurred. Here, we discuss possible source mechanisms, considering the temporal fluctuations in activity and observed seismogram characteristics.

One possible reason for icequakes near the ice-bedrock interface may be sudden slip motion of the glacier. Previously, such motions were studied under Antarctic ice streams (Anandakrishnan and Bentley, 1993; Anandakrishnan and 
Alley, 1994), which have a sliding component to their motion. Weaver and Malone (1979) concluded that seismic signals obtained from monitoring three Cascade volcanoes in Washington State, USA, also originated from such motion. Considering the signal characters, we now present evidence against such a source.

A slip motion is a shear failure near the base of the glacier. It produces a seismic radiation pattern consistent with a double-couple source (Aki and Richards, 1980) which is a function of the azimuth of the vector connecting source and recording station. This dependence manifests itself in a quadrantal azimuthal distribution of compressive and dilatational first arrivals of the seismic waves. Specifically, if the slip occurs in a plane parallel to the glacier bed and in the downhill direction, the first $\mathrm{P}$-wave motions uphill of the failure region will exhibit dilatational polarity, whereas those downhill of it are compressive (for a discussion of seismic radiation patterns of specific sources see Aki and Richards, 1980).

Anandakrishnan and Bentley (1993) noticed first-arrival patterns that are expected for slip motion under Ice Streams B and C, Antarctica. As far as the present study is concerned, all of the 2004 and the large majority of the 2006 basalcluster events show compressive first motions. Scrutinizing one of the 2004 basal clusters, it was found that slip motion in the direction of the bed inclination cannot produce compressive first arrivals at all stations (Gischig, 2007). Although full waveform inversions to calculate the seismic moment tensor are needed to rigorously describe the seismic sources of the basal-cluster events, the radiation pattern of first arrivals indicates that stick-slip motion is not responsible for the majority of basal-cluster events.

\subsection{Basal processes}

Tensile failures within the basal ice layer can produce compressive first motions at all azimuths and thus seem more plausible than shear failure. Hydrofracturing can cause these kinds of failures. For instance, pressurized water may enter pre-existing cracks and extend them. This process has been studied theoretically for surface and bottom crevasses (Van der Veen, 1998a,b, 2007). However, we also reject this kind of mechanism due to the diurnal activity of the basal-cluster events, which tends to peak at low or decreasing water pressures.

The dependence of glacier sliding on basal water pressure provides a better explanation than hydrofracturing. In the remainder of this discussion we make some propositions about how sliding may affect basal-cluster activity and what role basal water pressure might play.

Equation (1) is an empirical relation between sliding velocity $u$, basal shear stress $\tau$ and the difference between basal water pressure $p_{\mathrm{w}}$ and ice overburden pressure $p_{\mathrm{i}}$, also called effective pressure (Paterson, 1994):

$$
u=\mathrm{k} \tau^{p}\left(p_{i}-p_{w}\right)^{-q},
$$

where $p$ and $q$ are positive integers and $\mathrm{k}$ is a constant that depends on the thermal and mechanical properties of the glacier ice and increases with decreasing bed roughness.

According to Equation (1), sliding is drastically enhanced for subglacial water pressures approaching the ice overburden pressure, which is the case at or near the study sites of the present work (Fig. 7). If the water pressure reaches flotation level over a large enough region of the glacier bed, it can decouple the glacier from its bed. On the other hand, the large diurnal water-pressure drops near the bed lead to a strong decrease in sliding. As the basal ice layer couples to the bed again, it has to undergo large deformation rates, due to the braking action of the bedrock on the glacier base.

We suggest that this deformation of basal ice is responsible for its tensile fracturing and thus causes the basal-cluster icequakes. Although the coupling of the ice to the bed may primarily cause shear stresses, failure can still occur in the direction of maximum tension, similar to what is observed in the case of simple shear at glacier margins (Paterson, 1994). The high basal deformation might be favoured in distinct regions due to the presence of obstacles, high bed roughness or (spatially) unevenly distributed water masses. This can explain the clustering behaviour of these icequakes.

An interesting observation is that the locations of the 2006 clusters did not produce basal icequakes in 2004. An explanation may be the changing subglacial drainage system. At a certain time, a region of the glacier bed may be particularly well connected to the drainage system. The large diurnal basal water-pressure differences result in large deformation rates and fracturing of nearby basal ice during low water pressures. The drainage system may have changed in a subsequent year, and the large pressure fluctuations needed to cause fracturing of the basal ice layer are no longer occurring in this region.

Another explanation for basal-cluster events may be found in the evolution of water-filled cavities at the glacier bed. The bed near the seismic network may have too great an incline (Fig. 3) to allow basal water to accumulate and decouple the glacier over a large region. However, the large diurnal fluctuations in basal water pressure causing varying sliding velocity may still lead to large enough deformation rates of basal ice to cause basal-cluster events. During high basal water-pressure periods, water-filled cavities on the lee sides of bed undulations grow. Iken (1981) showed that this cavity growth greatly enhances sliding. As the pressure drops, the large hydrostatic pressure inside the basal glacier ice causes it to fill the cavities again. During this process, ice may actually flow 'uphill' into the cavity.

The large diurnal fluctuation of the basal water pressures suggests that water may leave such cavities rapidly. In this case, large deformation rates can be expected, as the basal ice closes the cavities rather quickly, possibly leading to basal-cluster events. This process may explain the observation that basal-cluster events occur as the surface lowers (Fig. 8). The small diurnal lifting and lowering of the surface may be due to the local evolution of cavities. In this case, the lowering would correspond to the closing of these cavities. It should be emphasized, however, that cavity creation is just one of the possible explanations for surface uplift. The latter may also be due to vertical straining, which has also been shown to vary on a diurnal scale (Sugiyama and Gudmundsson, 2003).

Generally, the basal ice beneath the study site can be expected to be particularly prone to large deformation rates. Whereas the glacier bed is strongly inclined, its surface is nearly horizontal in this region. Consequently, the ice thickness grows quickly in the down-glacier direction. The basal shear stress $\tau$ (Equation (1)) essentially has to support large parts of the downhill force on the ice. The downhill force, and hence the basal shear stress, increases with thickness. According to Equation (1), the sliding velocity also increases in the downhill direction, thus leading to stretching of the ice near the glacier bed. This can explain why the basal-cluster events can be expected in this particular part of the glacier. 


\section{CONCLUSION}

We have studied the effect of diurnal basal water-pressure variations and the drainage of a glacier-dammed lake on seismic emissions near the base of Gornergletscher. This investigation was part of a comprehensive field and modelling effort to understand the interaction of the Gornersee drainage with glacier dynamics and hydraulics. The seismic network thus operated concurrently with acquisition of GPS and borehole pressure data. This allowed for comparison of the glacier's seismic activity, dynamics and hydraulics.

No evidence was found that the passage of the lake water through or under the glacier caused brittle deformation radiating seismic energy. Instead, basal-cluster icequakes predominantly occurred during low or decreasing water pressure. No basal-cluster events were detected during water-pressure peaks caused by the lake drainage and daily surface melt. Therefore, we cannot report the detection of hydrofracturing of basal ice in the vicinity of the study site such as observed by Roberts and others (2000).

We explain the basal icequake activity detected on Gornergletscher by considering variations in sliding velocity caused by basal water-pressure fluctuations. This model assumes that deep basal icequakes are caused by tensile fracturing near the glacier bed, rather than by stick-slip motion. The compressive arrivals of $\mathrm{P}$-waves observed at all azimuths are also an indication of tensile faulting. Shear faulting as in the case of stick-slip motion would produce a quadrantal pattern of compressive and dilatational P-arrivals (Aki and Richards, 1980).

As a next step, full waveform inversions to estimate source properties should be made to further characterize icequake sources. In addition, numerical ice-flow models can help understand how large basal deformation rates can occur as basal hydrological conditions change. In this view, measurements from inclinometers installed inside the glacier during summer 2006 may be of great value. They also show diurnal signals which are likely to be induced by varying basal water pressures (M. Lüthi, unpublished information).

In any case, passive seismic measurements such as those described here provide a suitable means of studying basal processes. This is particularly interesting in the current study since the lake drainage causes an abrupt perturbation to the subglacial conditions which has a significant impact on the entire glacier.

\section{ACKNOWLEDGEMENTS}

The project was funded by the Swiss National Science Foundation under grant Nos 200021-103882/1 and 200020$111892 / 1$. We are grateful to many members of VAW, the Institute für Geophysik and the Swiss Seismological Service of ETH. By making their instruments available, H.-R. Maurer and the Applied and Environmental Geophysics group made the seismic measurements possible. Seismogram picking was done with the software package SNAP written by M. Baer. The Swiss military provided valuable help by transporting equipment via helicopter. The reviews of S. Anandakrishnan and M. Roberts were extremely helpful. We also thank M. Werder, M. Huss, A. Bauder, M. Lüthi, R. Gutzler, B. Nedela and J. Clinton for constructive comments during the preparation of the manuscript and for help during the field campaigns.

\section{REFERENCES}

Aki, K. and P.G. Richards. 1980. Quantitative seismology: theory and methods. San Francisco, W.H. Freeman and Co.

Anandakrishnan, S. and R.B. Alley. 1994. Ice Stream C, Antarctica, sticky spots detected by microearthquake monitoring. Ann. Glaciol., 20, 183-186.

Anandakrishnan, S. and C.R. Bentley. 1993. Micro-earthquakes beneath Ice Streams B and C, West Antarctica: observations and implications. J. Glaciol., 39(133), 455-462.

Aschwanden, A. 1992. Gletscherbeben: untersuchungen am Gornergletscher 1979. (Diplomarbeit thesis, VAW/ETH Zürich.)

Björnsson, H. 2002. Subglacial lakes and jökulhlaups in Iceland. Global Planet. Change, 35(3-4), 255-271.

Clarke, G.K.C. 2003. Hydraulics of subglacial outburst floods: new insights from the Spring-Hutter formulation. J. Glaciol., 49(165), 299-313.

Danesi, S., S. Bannister and A. Morelli. 2007. Repeating earthquakes from rupture of an asperity under an Antarctic outlet glacier. Earth Planet. Sci. Lett., 253(1-2), 151-158.

Deichmann, N., J. Ansorge, F. Scherbaum, A. Aschwanden, F. Bernardi and G.H. Gudmundsson. 2000. Evidence for deep icequakes in an Alpine glacier. Ann. Glaciol., 31, 85-90.

Gischig, V. 2007. Seismic investigations on Gornergletscher. (Diplomarbeit thesis, VAW/ETH Zürich.)

Haeberli, W. 1983. Frequency and characteristics of glacier floods in the Swiss Alps. Ann. Glaciol., 4, 85-90.

Huss, M. 2005. Gornergletscher: Gletscherseeausbrüche und Massenbilanzabschätzungen. (Diplomarbeit thesis, VAW/ETH Zürich.)

Huss, M., A. Bauder, M. Werder, M. Funk and R. Hock. 2007. Glacier-dammed lake outburst events of Gornersee, Switzerland. J. Glaciol., 53(181), 189-200.

Iken, A. 1981. The effect of the subglacial water pressure on the sliding velocity of a glacier in an idealized numerical model. J. Glaciol., 27(97), 407-421.

Lee, W.H.K. and S.W. Steward. 1981. Principles and applications in microearthquake networks. New York, Academic Press. (Advances in Geophysics 2.)

Métaxian, J.-P., S. Araujo, M. Mora and P. Lesage. 2003. Seismicity related to the glacier of Cotopaxi Volcano, Ecuador. Geophys. Res. Lett., 30(9), 1483. (10.1029/2002GL016773.)

Neave, K.G. and J.C. Savage. 1970. Icequakes on the Athabasca Glacier. J. Geophys. Res., 75(8), 1351-1362.

Nye, J.F. 1976. Water flow in glaciers: jökulhlaups, tunnels and veins. J. Glaciol., 17(76), 181-207.

O'Neel, S. and W.T. Pfeffer. 2007. Source mechanics for monochromatic icequakes produced during iceberg calving at Columbia Glacier, AK. Geophys. Res. Lett., 34(22), L22502. (10.1029/2007GL031370.)

O'Neel, S., H.P. Marshall, D.E. McNamara and W.T. Pfeffer. 2007. Seismic detection and analysis of icequakes at Columbia Glacier, Alaska. J. Geophys. Res., 112(F3), F03S23. (10.1029/2006JF000595.)

Paterson, W.S.B. 1994. The physics of glaciers. Third edition. Oxford, etc., Elsevier.

Raymond, M., M. Wegmann and M. Funk. 2003. Inventar gefährlicher Gletscher in der Schweiz. Mitt. VAW/ETH 182.

Richardson, S.D. and J.M. Reynolds. 2000. An overview of glacial hazards in the Himalayas. Quat. Int., 65/66(1), $31-47$.

Roberts, M.J. 2005. Jökulhlaups: a reassessment of floodwater flow through glaciers. Rev. Geophys., 43(1), RG1002. (10.1029/2003RG000147.)

Roberts, M.J., A.J. Russell, F.S. Tweed and O. Knudsen. 2000. Ice fracturing during jökulhlaups: implications for englacial floodwater routing and outlet development. Earth Surf. Process. Landf., 25(13), 1429-1446.

Smith, A.M. 2006. Microearthquakes and subglacial conditions. Geophys. Res. Lett., 33(24), L24501. (10.1029/2006GL028207.) 
Spring, U. and K. Hutter. 1981. Numerical studies of jökulhlaups. Cold Reg. Sci. Technol., 4(3), 227-244.

Stuart, G., T. Murray, A. Brisbourne, P. Styles and S. Toon. 2005. Seismic emissions from a surging glacier: Bakaninbreen, Svalbard. Ann. Glaciol., 42, 151-157.

Sugiyama, S. and G.H. Gudmundsson. 2003. Diurnal variations in vertical strain observed in a temperate valley glacier. Geophys. Res. Lett., 30(2), 1090. (10.1029/2002GL016160.)

Sugiyama, S. and G.H. Gudmundsson. 2004. Short-term variations in glacier flow controlled by subglacial water pressure at Lauteraargletscher, Bernese Alps, Switzerland. J. Glaciol., 50(170), 353-362.

Sugiyama, S., A. Bauder, P. Weiss and M. Funk. 2007. Reversal of ice motion during the outburst of a glacier-dammed lake on Gornergletscher, Switzerland. J. Glaciol. 53(181), 172-180.
Van der Veen, C.J. 1998a. Fracture mechanics approach to penetration of surface crevasses on glaciers. Cold Reg. Sci. Technol., 27(1), 31-47.

Van der Veen, C.J. 1998b. Fracture mechanics approach to penetration of bottom crevasses on glaciers. Cold Reg. Sci. Technol., 27(3), 213-223.

Van der Veen, C.J. 2007. Fracture propagation as means of rapidly transferring surface meltwater to the base of glaciers. Geophys. Res. Lett., 34(1), L01501. (10.1029/2006GL028385.)

Weaver, C.S. and S.D. Malone. 1979. Seismic evidence for discrete glacier motion at the rock-ice interface. J. Glaciol., 23(89), 171-184.

Weiss, P. 2005. Gletscherdynamik vor und nach der Entleerung des Gornersees im Sommer 2004. (Diplomarbeit thesis, VAW/ETH Zürich.)

MS received 29 August 2007 and accepted in revised form 21 March 2008 